\title{
0 positivismo na abordagem da recente historiografia gaúcha
}

Paulo Pezat *

Resumo: A influência exercida pelo positivismo sobre a sociedade gaúcha entre as décadas finais do século XIX e as iniciais do século XX é um dos traços mais característicos da história e da cultura do Rio Grande do Sul. Desde então, este tema tem motivado uma série de pesquisas e de obras da historiografia regional. Inicialmente as abordagens eram fortemente influenciadas pela conjuntura política e pela adesão ou rejeição ao projeto de poder implementado pelo Partido Republicano Rio-grandense no Rio Grande do Sul da Primeira República. Mais tarde, entre as décadas de 1970 e 1980, com uma maior profissionalização na área, muitos dos historiadores e dos cientistas sociais gaúchos que realizaram suas pesquisas de mestrado e de doutorado em outros estados do Brasil e mesmo no exterior centraram suas análises no período referido e, particularmente, nos reflexos que o pensamento de Auguste Comte deixou na política, na sociedade e na cultura do sul do país. Mais recentemente, a partir da criação e da consolidação no Rio Grande do Sul de programas de pós-graduação em História e em outras áreas das ciências humanas,

* Doutor em História pela Universidade Federal do Rio Grande do Sul. Professor do Departamento de História e Antropologia da UFPel.

Anos 90, Porto Alegre, v. 13, n. 23/24, p.255-285, jan./dez. 2006 
O positivismo na abordagem da recente historiografia gaúcha

o positivismo continua motivando novas pesquisas, baseando-se em acervos documentais antes indisponíveis e em novas abordagens teórico-metodológicas.

Palavras-chave: positivismo - historiografia - Rio Grande do Sul.

O presente artigo tem por objetivo fazer um balanço da recente produção historiográfica em torno da influência exercida pelo positivismo na sociedade gaúcha, além de resgatar alguns traços característicos deste campo de estudos desde suas origens e apresentar algumas conjecturas sobre possibilidades para futuras pesquisas. De fato, a influência exercida pelo pensamento de Auguste Comte no Rio Grande do Sul entre o final do século XIX e o início do século XX é um tema recorrente na historiografia gaúcha produzida desde então, motivando um grande número de estudos. Porém, antes de abordar a trajetória da historiografia acerca dos traços deixados pelo positivismo no sul do Brasil, é necessário desfazer alguns equívocos.

\section{- Positivismo e historiografia: uma aproximação ao tema}

Inicialmente, é preciso refletir acerca de uma idéia que continua sendo bastante popular, mesmo entre historiadores, qual seja a de que a historiografia produzida entre o final do século XIX e meados do século XX seria positivista. Cabe notar que tal afirmação invariavelmente é feita em tom pejorativo, com ares de superioridade. Quando se pede que essa suposta historiografia positivista seja caracterizada, é comum ouvir-se que ela seria factual, cronológica, nacionalista e edificante dos grandes líderes políticos e militares, exercendo a função de construir uma "história oficial" das classes dominantes. Tal apreciação é equivocada e denota que Comte é muito referido, mas pouco lido entre nós. Conforme assinalado por Sílvia Petersen, em nosso meio é comum a simplificação e repetição de idéias sem que se pergunte por 
Paulo Pezat

seus fundamentos, de modo que, de tanto se repetir, passam a ser verdades (Petersen, 1998, p. 31).

Uma leitura mais atenta das obras de Comte desmente vários aspectos comumente atribuídos ao seu pensamento. Em 1822, naquele que é considerado seu ensaio seminal, o Plano dos trabathos cientificos necessários para reorganizar a sociedade, o pensador francês escreveu:

"Todas as obras históricas escritas até hoje, mesmo as mais recomendáveis, não tiveram (...) senão o caráter de anais, isto é, de descrição e de disposição cronológica de uma certa série de fatos particulares, mais ou menos exatos, mas sempre isolados entre si. (...). Não existe até hoje verdadeira história, concebida em um espírito científico, isto é, tendo por fim a pesquisa das leis que presidem ao desenvolvimento social da espécie humana" (Comte, 1899, p. 199).

Como se pode perceber, Comte criticava na historiografia universal elaborada até o início do século XIX justamente alguns dos aspectos que as gerações posteriores atribuíram à influência do positivismo, como o caráter descritivo e o ordenamento cronológico. Notável também é a sua afirmação de que tais obras eram essencialmente literárias, isto é, que se inclinavam mais para o campo das artes do que para o campo das ciências.

Outra afirmação corriqueira nas críticas feitas à influência do positivismo na historiografia é que esta teoria atribuiria um papel determinante aos "grandes homens" no processo histórico. Tal idéia decorre do culto religioso de Comte aos indivíduos que representariam os distintos momentos da evolução humana, conforme o "calendário positivista". Mas, em uma outra passagem do aludido ensaio seminal, o filósofo francês assim expôs sua perspectiva acerca do papel do indivíduo na história: 
O positivismo na abordagem da recente historiografia gaúcha

“Tem sido a história escrita e estudada até o presente de um modo superficial (...). Esses fatos mal observados contribuem mesmo para manter ainda a crença teológica e metafísica no poder indefinido e criador dos legisladores sobre a civilização. (...). Este mau efeito resulta de que, nos grandes acontecimentos, vê-se unicamente os homens, e nunca as circunstâncias que os impelem com uma força irresistível. Em vez de reconhecer-se a influência preponderante da civilização, consideram-se os esforços desses homens previdentes como as verdadeiras causas dos aperfeiçoamentos realizados, que se teriam dado, um pouco mais tarde, sem a sua intervenção. (...). Apegam-se ao aparente, e desprezam o real, que está velado. (...). Quando o homem parece exercer uma grande ação, não é, em geral, por suas próprias forças, que são extremamente pequenas. São sempre forças exteriores que agem pelo homem, segundo leis sobre as quais ele nada pode" (Comte, 1899, p. 136-137).

É possível que muitos se surpreendam com a autoria do trecho citado, imaginando-o mais facilmente numa obra de Marx ou de Braudel. De fato, na passagem acima, é possível perceber que a supervalorização da ação dos "grandes homens" no processo histórico não encontra qualquer respaldo na obra de Comte. Longe de incentivar a prática do gênero biográfico na historiografia, Comte o entendia como uma forma superada e "metafísica" de perceber a história.

Com relação ao caráter nacionalista da suposta historiografia positivista, cabe lembrar que a exaltação dos nacionalismos era uma característica essencial da historiografia do século XIX, não se devendo especificamente ao positivismo de Comte, defensor da elaboração de uma história universal da humanidade. Da mesma forma, a tendência de centrar a análise nos fatos políticos é bem anterior, de forma alguma se devendo a uma influência específica do pensamento de Comte. 
Desse modo, creio que fica demonstrado o equívoco de se conceituar como "positivista" a historiografia desenvolvida ao longo do século XIX e de boa parte do século XX, pois esse é um rótulo que promove uma homogeneização inexistente na prática, além de atribuir ao pensamento comtiano idéias que são anteriores e muitas que lhe contradizem frontalmente. Assim, se a narrativa linear, a rigorosa cronologia, o empirismo e a exaltação dos "grandes heróis da pátria" foram hegemônicos na prática historiográfica do final do século XIX e do começo do século XX (de forma universal, e não apenas no Rio Grande do Sul), isto se deveu não à influência direta do positivismo, mas à recorrência de uma série de tendências presentes na historiografia desde suas raízes na Grécia Antiga, conforme assinalou Ieda Gutfreind em análise dessa questão feita há alguns anos, na qual sugere que tal historiografia seja caracterizada pelo vocábulo "tradicional" (Gutfreind, 1998, p. 57).

\section{- Positivismo e castilhismo na historiografia gaúcha da primeira metade do século XX}

Deixando de lado aqueles escritos elaborados no calor dos acontecimentos que marcaram a ascensão, destituição, retomada e exercício do poder por parte de Júlio de Castilhos na última década do século XIX, bem como os textos de natureza política de autoria de adeptos do Partido Republicano Rio-grandense (PRR) e de seus opositores nas primeiras décadas do século XX, assim mesmo é bastante relevante a produção em torno da influência exercida pelo pensamento de Auguste Comte na sociedade gaúcha do período aludido.

Especificamente no âmbito da historiografia produzida no Rio Grande do Sul da primeira metade do século XX, cabe inicialmente lembrar que ela foi desenvolvida essencialmente por 
O positivismo na abordagem da recente historiografia gaúcha

historiadores não-profissionais, notadamente por literatos, jornalistas, advogados, militares e clérigos, na qual a análise imparcial muitas vezes era obscurecida pelas paixões decorrentes da simpatia ou da antipatia pelo projeto político de inspiração positivista desenvolvido por Júlio de Castilhos à frente do PRR nos tempos iniciais da República no sul do país, período que a quase totalidade dos aludidos autores vivenciou. A partir de 1920, com a criação do Instituto Histórico e Geográfico do Rio Grande do Sul (IHGRS) e de sua revista trimestral, tal produção historiográfica encontrou um espaço de veiculação. O IHGRS desempenhou um papel catalisador ao promover a reunião em seus quadros entre intelectuais identificados com o PRR e intelectuais que se opunham ao projeto político castilhista. Desse modo, constituiu-se em uma base importante para a posterior aproximação entre as distintas facções oligárquicas do Rio Grande do Sul e para a criação da Frente Única Gaúcha em torno de Getúlio Vargas no final daquela década. Entretanto, a produção historiográfica sul-riograndense daquele período acerca da influência exercida pelo positivismo e dos eventos políticos no Estado nos tempos iniciais da República permaneceu influenciada pelas opções políticas de seus autores (Almeida, 1987). Nesse sentido, cabe ressaltar que os ódios políticos fomentados pela Revolução Federalista, entre 1893 e 1895, foram retomados no contexto da Revolução de 1923, dificultando a elaboração de análises históricas distanciadas da conjuntura política polarizada que ainda caracterizava o Rio Grande do Sul.

No princípio da década de 1980, a partir de uma perspectiva gramsciana, Sandra Pesavento assinalou o pouco interesse que a historiografia gaúcha produzida até a década de 1960 tinha pelos eventos do início do período republicano, visto que a atenção estava voltada primordialmente para temas como a formação histórica do "Continente do Rio Grande", a colonização açoriana, as guerras travadas entre portugueses e espanhóis pelo domínio da 
região platina e a Revolução Farroupilha. Ou seja, tal historiografia estava interessada centralmente no período "épico" da história do Rio Grande do Sul. Desse modo, os historiadores legitimavam a hegemonia da oligarquia e de outros grupos dominantes em detrimento dos subalternos, cuja presença no território gaúcho chega a ser negada. Conforme referiu, a opção por tais temáticas decorreria de um certo alheamento dos historiadores frente à realidade econômica e social do Rio Grande do Sul posterior à Primeira Guerra Mundial, marcada pela defasagem em relação ao salto de industrialização que ocorria em São Paulo (Pesavento, 1980, p. 87).

Deixando de lado esses aspectos mais gerais da historiografia produzida no Rio Grande do Sul durante a primeira metade do século XX (e mesmo um pouco depois) e abordando especificamente aquelas obras que se debruçaram sobre a República Velha gaúcha, cabe destacar a ausência de qualquer obra que procurasse fazer uma aproximação entre os postulados de Auguste Comte e sua interpretação pelos republicanos do Rio Grande do Sul. Em contrapartida, proliferaram os estudos centrados na ação de Júlio de Castilhos e de Borges de Medeiros, os dois governantes que emblematizaram a influência política do positivismo comtiano no Rio Grande do Sul, o primeiro como intérprete e o segundo como executor. Nesse sentido, significativa é a obra Júlio de Castilhos perfil biographico e escriptos politicos, de autoria de Othelo Rosa, adepto do PRR e vice-diretor do IHGRS, na qual são resgatados diversos textos e pronunciamentos em que Castilhos explicitou sua adesão à filosofia positivista concebida por Auguste Comte (Rosa, 1928 , p. 33). Não menos emblemática é a biografia oficial do sucessor de Castilhos intitulada Borges de Medeiros - subsídios para o estudo de sua vida e de sua obra, de autoria de João Pio de Almeida, secretário particular daquele que governou o Rio Grande do Sul durante um quarto de século durante a Velha República (Almeida, 1928). Tais obras, embora os personagens biografados fossem simpáticos ao positivismo, nada têm de "positivistas" no sentido 
O positivismo na abordagem da recente historiografia gaúcha

teórico-metodológico concebido por Comte, apresentando a concepção tradicional de edificação do "grande homem" tal como referido anteriormente.

De outra parte, deixando de lado aqueles textos elaborados no calor do combate e imediatamente veiculados em jornais gasparistas, tais como os escritos de Epaminondas Villalba e de Antônio Augusto de Carvalho, uma obra merece especial referência no contexto da historiografia sobre os primórdios da República no Rio Grande do Sul identificada com as forças de oposição ao castilhismo. Trata-se dos Apontamentos para a história da revolução Rio-Grandense de 1893, de Wenceslau Escobar, obra publicada em 1920, quando o autor ocupava uma vaga na bancada oposicionista na Câmara dos Deputados, no Rio de Janeiro. Nesta obra Escobar relata episódios sangrentos do conflito, principalmente aqueles em que as forças oposicionistas foram massacradas pelas forças castilhistas, chamadas de sanguinárias e de sectárias de uma doutrina estranha aos ideais do povo brasileiro (Escobar, 1920).

\section{- O positivismo na abordagem acadêmica das décadas de 1950 e 1960}

Pode-se dizer que as décadas de 1950 e de 1960 marcaram a transição entre as abordagens elaboradas pela tradicional historiografia gaúcha, produzida na primeira metade do século XX, e aquela elaborada por pesquisadores profissionais, que se consolidou nas décadas de 1970 e 1980, pois apresentou o convívio de análises ainda influenciadas pela identificação ou rejeição ao projeto político do PRR com abordagens mais distanciadas, fruto de intensas pesquisas documentais.

Nesse sentido, inicialmente merece referência a palestra proferida por Florêncio de Abreu na Federação das Academias de Letras do Brasil, em 1955, publicada sob o título O movimento 
positivista no Rio Grande do Sul em uma coletânea de ensaios editada em 1964. Florêncio de Abreu desenvolveu boa parte de sua vida profissional exercendo funções relacionadas ao projeto político do PRR, seja como diretor do Arquivo Público durante o governo de Borges de Medeiros, seja como chefe de polícia durante o governo de Getúlio Vargas. Abreu começa o referido ensaio resgatando alguns traços mais gerais da filosofia de Auguste Comte para depois destacar a "profissão de fé comtiana" feita por Demétrio Ribeiro e por Júlio de Castilhos, como demonstraria o artigo assinado pelos dois em $A$ Federação de 5 de setembro de 1888, data do trigésimo primeiro aniversário da "transformação subjetiva" do filósofo de Montpellier. Mais adiante, Abreu destaca a proximidade existente entre Demétrio Ribeiro e o fundador da Igreja Positivista do Brasil, Miguel Lemos, colegas na Escola Politécnica do Rio de Janeiro e íntimos amigos. O rompimento entre ambos ocorreu quando Demétrio negou-se a apoiar o projeto de constituição elaborado por Castilhos e passou a contestar a hegemonia deste sobre o PRR, o que ocasionou sua saída do partido e seu posterior apoio às forças federalistas durante a revolução de 189395. Um aspecto interessante do artigo de Abreu, que é extremamente factual, é o resgate que promove de alguns aspectos geralmente pouco referidos, como a ação do grupo de positivistas religiosos gaúchos filiados à Igreja Positivista do Brasil no âmbito do projeto político do PRR (Abreu, 1964, p. 231-233).

Em 1958, ao publicar sua História Geral do Rio Grande do Sul, abordando o período inicial da República no Estado, Arthur Ferreira Filho referiu que "como governante, Júlio de Castilhos imprimiu na administração rio-grandense um traço tão fundo de austeridade que, apesar de tudo, ainda não desapareceu" (Ferreira Filho, 1958, p. 149). Justificou tal afirmação dizendo que, para Castilhos, a República era o "reino da virtude" onde somente os puros e desambiciosos deveriam exercer funções de governo, concepção esta derivada da influência que recebera do positivismo comtiano. 
O positivismo na abordagem da recente historiografia gaúcha

Apesar de não esconder sua admiração por Castilhos e pelo castilhismo, Ferreira Filho apóia sua obra em pesquisas e não se furta de tecer críticas ao governo gaúcho da Velha República e de registrar a violência praticada nas revoluções de 1893 e de 1923.

Em 1967, Sérgio da Costa Franco publicou Júlio de Castilhos e sua época, obra apoiada em ampla pesquisa documental e bibliográfica que veio trazer novas luzes para o estudo da trajetória da principal liderança do PRR, até então abordada de forma central apenas por Othelo Rosa na obra antes referida. Cabe notar que o autor desenvolveu a pesquisa e a redação do livro à margem do ambiente universitário, paralelamente às suas atividades profissionais no poder judiciário estadual. A obra tornou-se um marco nos estudos sobre a história do Rio Grande do Sul entre a década final do Império e a década inicial da República ao salientar a interpretação singular do pensamento de Comte feita por Júlio de Castilhos e sua adaptação ao contexto social sul-rio-grandense. Destacou também a influência do positivismo na criação do aparato burocrático estadual e na modernização da infra-estrutura do Rio Grande do Sul.

Naquele mesmo ano, no Rio de Janeiro, igualmente atuando no poder judiciário, porém em nível nacional, Ivan Lins redigiu a sua História do positivismo no Brasil, na qual destinou um capítulo para tratar do positivismo no Rio Grande do Sul (Lins, 1967, p. 175-203). Embora Lins seja alheio à historiografia sul-riograndense, seu nome não pode deixar de ser referido por ser a obra acima referida um clássico sobre a influência do pensamento de Comte no Brasil. Esse trabalho tem o mérito de se basear num conhecimento amplo da documentação sobre o tema, fruto de um convívio pessoal bastante estreito com seguidores de diferentes vertentes da doutrina comtiana, constituindo-se em obra fundamental para o estudo do tema, apesar da identificação um tanto demasiada de seu autor com o objeto de estudo. No que tange ao Rio Grande do Sul, sua obra merece destaque por registrar a 
existência de clubes republicanos fortemente influenciados pelo positivismo em cidades como Rio Grande, Bagé e Caçapava, tema praticamente ignorado pela historiografia produzida no sul do país.

\section{- O positivismo na abordagem acadêmica das décadas de 1970 e 1980}

Ao longo da década de 1970 consolidaram-se as condições

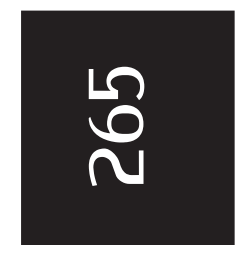
para que surgisse no Rio Grande do Sul a primeira geração de historiadores e de cientistas sociais com formação profissional específica e que atuava prioritariamente no ensino e na pesquisa da História e das distintas Ciências Sociais.

Entretanto, antes que esses pesquisadores gaúchos publicassem tais estudos, a temática da influência exercida pelo pensamento de Auguste Comte na sociedade gaúcha da República Velha já despertara a atenção de estudiosos de fora do Rio Grande do Sul. Nesse sentido, durante o final da década de 1960, o historiador norte-americano Joseph Love desenvolveu em arquivos do Rio Grande do Sul e do Rio de Janeiro a pesquisa que resultou na tese intitulada Rio Grande do Sul and Brazilian Regionalism, defendida em 1971 na Stanford University e publicada alguns anos depois no Brasil com o título $O$ regionalismo gaúcho e as origens da revolucão de 1930. Nessa obra, Love mapeou as origens sociais das principais lideranças republicanas e assinalou a convergência entre os seus interesses de classe e o projeto político conservador concebido por Comte. De fato, o positivismo comtiano defendia o alijamento das classes populares em relação aos assuntos governamentais, que deveriam ficar sob a responsabilidade de homens públicos moralizados e conhecedores das leis que regulariam a natureza e a vida em sociedade, que o filósofo francês acreditava haver apreendido (Love, 1975). 
O positivismo na abordagem da recente historiografia gaúcha

Em meados da década de 1970, o historiador colombiano Ricardo Vélez Rodríguez também se interessou pelo estudo do fenômeno castilhista no Rio Grande do Sul da Velha República, publicando em 1980 a obra Castillismo - uma filosofia da República, na qual ressaltou que não foram apenas as idéias de Comte que se difundiram no sul do país entre as últimas décadas do século XIX e as décadas iniciais do século XX. De fato, havia um "surto de novas idéias" que acompanhou a propaganda republicana durante o Segundo Reinado, havendo em comum entre elas a inspiração cientificista. Dentre tais correntes de pensamento, além do positivismo, encontravam adeptos no Rio Grande do Sul o spencerianismo, o naturalismo, o darwinismo social, o monismo de Haeckel, o saint-simonismo, o socialismo e o anarquismo. Porém, conforme assinalou Vélez Rodríguez, deposta a monarquia, no momento de dar feição republicana às instituições políticas e sociais do Rio Grande do Sul, Castilhos e o PRR inspiraram-se essencialmente no positivismo comtiano (Rodríguez, 1980, p. 32). É importante ressaltar que o trabalho apóia-se em leituras do próprio filósofo francês, aspecto nem sempre respeitado por historiadores que se propõem a estudar a influência positivista no Rio Grande do Sul.

De acordo com a análise retrospectiva feita por Sandra Pesavento nos últimos anos do século XX, na década de setenta os historiadores e demais pesquisadores do campo das ciências humanas estavam preocupados em elucidar as origens do capitalismo no Brasil, as especificidades do seu processo de industrialização e da formação das classes sociais, bem como resgatar as raízes do autoritarismo no país. Nesse sentido, boa parte das pesquisas com vistas à elaboração de dissertações de mestrado e de teses de doutorado desenvolvidas por historiadores gaúchos na década de setenta voltaram-se para o estudo da República Velha, em busca de dados que explicassem a tradição autoritária do Rio Grande do Sul (lembrando que o Estado forneceu três generais 
que ocuparam a presidência da República durante a ditadura militar) e a consolidação do capitalismo na região (Pesavento, 1998, p. $59-60){ }^{1}$

De parte dos historiadores e cientistas sociais, a década de 1970 foi abundante em estudos que referiam a difusão e impacto do positivismo comtiano no Rio Grande do Sul. ${ }^{2}$ A proliferação de estudos foi decorrente da criação do curso de mestrado em História na Pontifícia Universidade Católica do Rio Grande do Sul (PUCRS) em meados da década de 1970, que produziu suas pri-

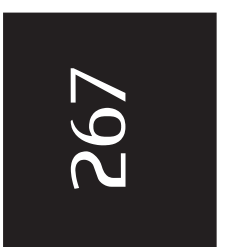
meiras dissertações alguns anos após. Conforme observou Sandra Pesavento, "uma história econômico-social, de inspiração marxista, conjugava-se a um viés político de análise, revigorado pela incorporação da contribuição gramsciana", tendo como pano de fundo a conjuntura do autoritarismo dos governos militares. Neste contexto, em 1977, Luiza Kliemann defendeu a dissertação de mestrado intitulada A ferrovia gaúcha e as diretrizes de Ordem e Progresso, na qual procurou demonstrar como o positivismo, enquanto ideologia política, norteou a ação do estado intervencionista no sentido de estabelecer uma infra-estrutura que alavancasse a modernização e o desenvolvimento da economia do Rio Grande do Sul (Kliemann, 1977).

Sandra Pesavento concluiu a dissertação de mestrado na PUCRS em 1978, intitulada Charqueadas, frigorificos e criadores - um estudo sobre a República Velha Gaúcha, ${ }^{3}$ na qual analisou as transformações ocorridas na tradicional economia pecuarista e charqueadora do Rio Grande do Sul a partir da introdução dos frigoríficos, no contexto da Primeira Guerra Mundial. Relativamente ao positivismo, neste trabalho merece atenção a análise da política tributária posta em vigor pelo governo estadual. No mesmo ano, Heloísa Reichel defendeu a dissertação $A$ indústria têxtil no Rio Grande do Sul: 1910-1930, procurando destacar a busca de participação da economia gaúcha na economia nacional através de exportações para fora do estado e do país. ${ }^{4}$ 
O positivismo na abordagem da recente historiografia gaúcha

Diferentemente dos estudos referidos acima, situados no âmbito da história econômica e social, a dissertação de mestrado em Ciência Política de Céli Pinto defendida na UFRGS, em 1979, sob o título Contribuição ao Estudo da Formação do Partido Republicano Rio-grandense adotou uma perspectiva de análise mais centrada nos aspectos políticos e ideológicos. Entretanto, os aspectos econômicos não foram inteiramente deixados de lado, tal como demonstra o levantamento que realizou dos inventários de bens de algumas das principais lideranças republicanas (Pinto, 1979). Em linha que também privilegiava uma abordagem no campo intelectual, a dissertação de mestrado em História defendida por Ieda Gutfreind na PUCRS, em 1979, recebeu o título Rio Grande do Sul, 1889-1896: a proclamação da República e a reação liberal através de sua imprensa. No trabalho, amparado em ampla pesquisa hemerográfica, Gutfreind destaca a disputa ideológica travada no Rio Grande do Sul do princípio da República entre os liberais liderados por Gaspar Silveira Martins e os republicanos liderados por Júlio de Castilhos, respectivamente através das páginas dos jornais $A$ Reforma e $A$ Federação. Alguns anos depois, em 1982, também na PUCRS e igualmente apoiada em ampla pesquisa de jornais, Margaret Bakos defendeu a dissertação de mestrado em História intitulada Republicanismo, Positivismo e imprensa político-partidária no Movimento Abolicionista no RS (1870-1888), na qual destacou a especificidade da influência do ideário comtiano sobre o movimento de abolição da escravidão no Rio Grande do Sul. ${ }^{5}$

$\mathrm{Na}$ maior parte desses trabalhos, o positivismo era um fator de análise importante, mas não o central. Nesse sentido, diferenciado foi o artigo O Rio Grande de Augusto Comte, publicado por Nelson Boeira em 1980, em um dos volumes da célebre coleção "Documenta", editada pela Editora Mercado Aberto na passagem dos anos setenta para os anos oitenta, reunindo pesquisas acadêmicas sobre a história do Rio Grande do Sul. Em decorrência de sua formação em Filosofia, Boeira revela profundo conhecimento 
dos meandros do pensamento de Auguste Comte. Mas não se contenta em fazer uma abordagem filosófica pura do positivismo. Ao contrário, seu interesse está em verificar as diferentes maneiras como este sistema de idéias foi lido e interpretado por variados atores sociais no Rio Grande do Sul do período final do Império e inicial da República, estabelecendo uma sintonia fina na interpretação do fenômeno do impacto do positivismo sobre a sociedade gaúcha. Em especial, chama a atenção a análise das influências religiosas e estéticas deixadas pelo positivismo no Rio Grande do Sul, tendo em vista que a maior parte dos estudos fixa-se especificamente nos aspectos políticos. Também é interessante notar a importância que dá à periodização, destacando o fato de que a influência exercida pelo pensamento de Auguste Comte sobre a sociedade gaúcha não foi uniforme, havendo deslocamentos de sentidos e de interpretações do mesmo (Boeira, 1980, p. 45-59).

Em 1986, Céli Pinto defendeu sua tese de doutorado em História na University of Essex, sob o título Positivism - an alternative political project in the Old Republic in Brazil, ${ }^{6}$ trabalho no qual destacou o importante papel exercido pelo jornal $A$ Federação como instrumento de doutrinação do PRR e demonstrando o ritmo oscilante com que o fervor positivista se manifestava nos artigos veiculados, de acordo com as variações na conjuntura política (Pinto, 1986).

Também em 1986, Luiza Kliemann defendeu na USP a tese de doutorado em História que resultou, no mesmo ano, na publicação do livro RS: terra e poder - bistória da questão agrária no Rio Grande do Sul, na qual detalhou as políticas fundiária e de colonização postas em prática pelo PRR, revelando suas relações com o positivismo comtiano. No ano seguinte, também na USP, duas teses de doutorado trouxeram dados fundamentais para o entendimento da República Velha gaúcha. No âmbito da análise econômica, a tese Empresariado industrial, trabalho e Estado: contribuição a uma análise da burguesia industrial gaúcha, de Sandra Pesavento, 
O positivismo na abordagem da recente historiografia gaúcha

revelou as relações de colaboração e conflito que se sucederam entre trabalhadores, empresários industriais e o poder público na República Velha gaúcha. ${ }^{7}$ Já no âmbito político, a tese de doutorado de Loiva Otero Félix esmiuçou as relações existentes entre a cúpula do PRR e as lideranças regionais do norte do Rio Grande do Sul, demonstrando a distância existente entre o ideário comtiano e as necessidades de barganha impostas pelo pragmatismo político. $^{8}$

Finalizando aquela década, merece destaque o artigo $O$ jacobinismo castilhista e a ditadura positivista no Rio Grande do Sul, publicado por Hélgio Trindade em 1990, a partir de uma palestra realizada no ano anterior na França, no colóquio internacional Auguste Comte: philosophie et révolution, alusivo ao bicentenário da Revolução Francesa. A análise procura contextualizar a influência que o positivismo deixou na América Latina, especialmente no México, no Chile, na Argentina, no Uruguai e no Brasil. Mas destaca que o Rio Grande do Sul foi um caso excepcional, em função da duração e da profundidade dos traços deixados pelo pensamento de Auguste Comte na organização social do estado. Em especial, procura caracterizar a interpretação e a adaptação do positivismo comtiano feita por Júlio de Castilhos, tomando a análise da Constituição sul-rio-grandense de 14 de julho de 1891 como documento-chave para entender a estratégia política adotada pelo PRR (Trindade, 1990, p. 96-101).

Embora se situe cronologicamente em um período posterior e não seja de um autor identificado com a historiografia gaúcha, o ensaio Arqueologia do Estado-Providência, que o professor de literatura da USP Alfredo Bosi publicou em 1992, merece ser situado aqui em função da posição que o seu autor ocupa na comunidade acadêmica. De fato, o referido texto traz uma grande contribuição à historiografia sul-rio-grandense ao analisar o fenômeno da influência do ideário positivista no sul do país a partir de uma perspectiva de longa duração, cotejando a experiência política 
desenvolvida pelo PRR na República Velha gaúcha com outras experiências de modernização nas quais o poder executivo tomou um papel preponderante, como foram os casos das industrializações da França, da Alemanha e da Rússia/URSS entre o final do século XIX e o começo do século XX (Bosi, 1992, p. 275).

\section{- O positivismo na abordagem da recente historiografia gaúcha}

A partir da década de 1990, com a consolidação de diversos programas de pós-graduação em História no Rio Grande do Sul, obviamente proliferou a produção historiográfica acadêmica, o que acabou por se refletir em uma significativa produção em torno dos traços deixados pelo pensamento de Auguste Comte no sul do país. Cabe registrar que muitos desses estudos desenvolvidos nos últimos dez ou quinze anos ocorreram sob a orientação daqueles pesquisadores que elaboraram suas dissertações de mestrado e de doutorado nas décadas de 1970 e de 1980.

Este foi o meu caso particular. A partir do final da década de 1980, ainda cursando a graduação em História na UFGRS, comecei a pesquisar a política indigenista implementada pelo poder público no Rio Grande do Sul durante o Segundo Império e a República Velha, orientado pela Profa Luiza Kliemann, que recém havia concluído sua tese de doutorado sobre a questão fundiária no Rio Grande do Sul. Foi neste contexto que descobri a figura de Carlos Torres Gonçalves, que veio a ser central em minhas pesquisas alguns anos mais tarde. No começo da década seguinte, inicialmente sob a orientação da Prof ${ }^{a}$ Helga Piccolo e depois com a orientação da Prof ${ }^{a}$ Sandra Pesavento, passei a desenvolver no Programa de Pós-Graduação em História desta mesma universidade minha pesquisa de mestrado, em torno da influência do positivismo sobre a política indigenista implementada pelo governo 
O positivismo na abordagem da recente historiografia gaúcha

estadual durante a República Velha. Foi então que descobri que Torres Gonçalves, além de engenheiro e funcionário público estadual, fora um dos principais representantes da Igreja Positivista do Brasil no Rio Grande do Sul e o principal responsável pela construção da Capela Positivista de Porto Alegre, em cujo acervo passei a pesquisar com regularidade.

Neste contexto, em colaboração com a colega Elisabete Leal e com o apoio do PPG-História da UFRGS, da FAPERGS e do Fumproarte, ${ }^{9}$ foi desenvolvido um trabalho de levantamento, de organização e de publicação de um catálogo do acervo da Capela Positivista de Porto Alegre, um dos raros templos de culto à religião criada por Auguste Comte que existem no mundo. ${ }^{10}$ As pesquisas desenvolvidas a partir dos documentos e das obras editadas pela Igreja Positivista do Brasil em Porto Alegre, no Rio de Janeiro e em Paris contribuíram para o desenvolvimento de diversas dissertações de mestrado e teses de doutorado elaboradas no Rio Grande do Sul a partir dos anos 1990.

Embora não tenha a pretensão de conhecer toda a produção acadêmica relevante em torno dos traços deixados pelo positivismo na história do Rio Grande do Sul, creio que quinze anos de pesquisa em torno do tema me permitem ter uma visão mais ou menos ampla sobre as obras recentemente produzidas, que alinhavo rapidamente a seguir.

Em 1995, na PUCRS, Clarisse Ismério Roznieski defendeu sua dissertação de mestrado com o título $A$ mulher na república veIha: o imaginário e a realidade no RS (1889-1930), na qual destacou os aspectos retrógrados que o positivismo comtiano teria legado para a educação feminina no Rio Grande do Sul do início da República, face à maior liberdade desfrutada pelas mulheres no período de formação da sociedade gaúcha e da Revolução Farroupilha. ${ }^{11}$

Também na perspectiva da situação da mulher no Rio Grande do Sul da República Velha e pertencendo a esta nova geração de historiadores, Elisabete Leal defendeu no PPG-História 
da UFGRS, em 1996, a dissertação de mestrado intitulada O positivismo, o Partido Republicano Rio-Grandense, a moral e a mulber (18911913), na qual analisou centralmente os artigos veiculados pelo jornal $A$ Federação acerca da situação da mulher na sociedade moderna, cotejando tais textos com as políticas implementadas pelo PRR, com os escritos de Auguste Comte e com as publicações da Igreja Positivista do Brasil.

Em 1997, defendi minha dissertação de mestrado sob o título Auguste Comte e os fetichistas: estudo sobre as relações entre a Igreja Positivista do Brasil, o Partido Republicano Rio-grandense e a política indigenista na República Velha. Foi uma tentativa de desenvolver um estudo no campo da história das idéias, procurando verificar a forma como o ideário concebido por Comte na França da primeira metade do século XIX - mais especificamente sua filosofia da história, calcada na "lei dos três estados" - foi importado e adaptado pelos fundadores da Igreja Positivista do Brasil, no Rio de Janeiro do final do período Imperial, chegando a Porto Alegre no princípio do século XX e sendo assimilado por um grupo de engenheiros/ funcionários públicos estaduais, e, finalmente, inspirando a política indigenista implementada na região norte do Rio Grande do Sul. Passada já quase uma década da elaboração deste trabalho, suas deficiências ficam claras, principalmente no primeiro capítulo, marcado por uma leitura ainda muito superficial da obra de Comte. Em contrapartida, se o trabalho ainda apresenta alguma validade, creio que ela decorre da exploração dos documentos existentes nos acervos do Templo da Humanidade do Rio de Janeiro (sede da Igreja Positivista do Brasil) e da Capela Positivista de Porto Alegre, que possibilitam uma melhor compreensão da trajetória feita pelo pensamento de Comte desde o momento de sua importação e adaptação ao contexto brasileiro e gaúcho do final do século XIX e começo do século XX.

Também em 1997, Beatriz Weber defendeu na UNICAMP a tese de doutorado em História intitulada As artes de curar: medicina, 
O positivismo na abordagem da recente historiografia gaúcha

religião, magia e positivismo na República Rio-Grandense (1889-1928), na qual evidenciou as dificuldades enfrentadas pelos governantes republicanos em manterem-se fiéis aos ideais positivistas frente às pressões sociais que recebiam, notadamente em relação às reivindicações dos médicos para que o poder público estadual proibisse o curandeirismo, coisa que se chocava com o princípio comtiano consagrado pela constituição castilhista de 14 de julho de 1891 que estabeleceu o princípio da liberdade profissional.

No PPG-História da Unisinos, César Jungblut defendeu, no ano de 1998, a dissertação de mestrado intitulada "Júlio de Castilhos ainda vive?" - Imaginário político da República Velha Rio-Grandense (1903-1923), representativa da tendência de desenvolvimento da história das sensibilidades e de exploração das dimensões simbólicas do poder.

Naquele mesmo ano, Mozart Pereira Soares publicou $O$ positivismo no Brasil: 200 anos de Augusto Comte, fruto de uma vivência e de uma identificação com os círculos positivistas de mais de meio século. A parte referente ao positivismo no Rio Grande do Sul pode ter sua importância equiparada ao significado que a obra de Ivan Lins teve para o estudo do positivismo em âmbito nacional, por reproduzir ampla e rica documentação.

Em 2000, Breno Sponchiado defendeu na PUCRS a dissertação de mestrado em História intitulada $O$ positivismo e a colonização do norte do Rio Grande do Sul, onde evidenciou a importância de Carlos Torres Gonçalves para o delineamento das características da política fundiária posta em prática pelo PRR ao longo da República Velha, destacando-se a análise da criação das colônias que originaram as cidades de Erechim, Santa Rosa e Iraí, nas quais o engenheiro gaúcho deixou marcos identificadores da influência que recebeu de Auguste Comte (Sponchiado, 2000).

No ano seguinte, no Programa de Pós-graduação em História Social da USP, Gunter Axt defendeu a tese Gênese do Estado burocrático-burguês no Rio Grande do Sul (1889-1929), na qual 
procurou analisar a construção da hegemonia política e econômica das frações de classe dominante que se organizaram em torno do projeto político do PRR ao longo da República Velha, período em que ocorreu a consolidação do aparelho de estado burguês no Rio Grande do Sul. O autor analisa ainda a importância das políticas públicas de tributação para a estruturação dos setores de transporte e de energia, essenciais à modernização do estado. No ano seguinte, Axt publicou o artigo Os guardiães da lei: aspectos da influência política e cultural dos positivistas religiosos sobre os governos republicanos no Rio Grande do Sul, no qual procurou fazer uma análise gramsciana do papel de "intelectuais orgânicos" desempenhado pelos positivistas ortodoxos gaúchos junto ao projeto político desenvolvido pelo PRR.

Em 2003, defendi a minha tese de doutorado no PPG-História da UFRGS sob o título Carlos Torres Gonçalves, a familia, a pátria e a bumanidade: a recep̧cão do positivismo por um filho espiritual de Auguste Comte e de Clotilde de Vaux no Brasil (1875-1974), ${ }^{12}$ um estudo biográfico do mais destacado positivista religioso gaúcho. Além de suas atividades públicas no âmbito do aparelho burocrático do PRR, na condição de funcionário público e de engenheiro da Secretaria de Obras Públicas, onde exerceu a chefia da Diretoria de Terras e Colonização por mais de duas décadas, e de sua ação proselitista como membro da Igreja Positivista do Brasil e adepto da Religião da Humanidade, o trabalho também procura perceber a forma como Torres Gonçalves incorporou o positivismo comtiano aos aspectos privados de sua existência, mais particularmente na sua vida familiar. Para isso, além das pesquisas que já tinha desenvolvido anteriormente nos arquivos públicos do Rio Grande do Sul e nos acervos da Igreja Positivista do Brasil no Rio de Janeiro e em Porto Alegre, foi fundamental o contato com os seis filhos de Torres Gonçalves, que me possibilitaram o acesso aos documentos e à memória preservada pela família. 
O positivismo na abordagem da recente historiografia gaúcha

No ano seguinte, Ernesto Cassol publicou o livro Carlos Torres Gonçalves, vida e obra, analisando de forma mais detida a ação de Torres Gonçalves na colonização da região norte do Rio Grande do Sul, especialmente em Erechim, colônia por ele criada e onde homenageou Paris (a Meca do Ocidente, de acordo com Auguste Comte) no seu traçado urbano. O trabalho apóia-se em ampla pesquisa na documentação da Comissão de Terras de Erechim.

Em 2004, Débora Dinnebier defendeu na PUCRS sua dissertação de mestrado, intitulada Júlio de Castilhos e a Igreja Positivista do Brasil: diálogos de aproximacõoes e divergências, na qual, a partir de pesquisas realizadas no Museu Júlio de Castilhos e na Capela Positivista de Porto Alegre, procurou compreender as relações estabelecidas entre o projeto político desenvolvido pelos positivistas heterodoxos gaúchos, reunidos no PRR sob a liderança de Júlio de Castilhos, e os positivistas religiosos, reunidos na Igreja Positivista do Brasil sob a liderança de Miguel Lemos e de Teixeira Mendes.

\section{- Balanço da produção recente e perspectivas futuras}

Fazendo um balanço da trajetória dos estudos sobre a influência do pensamento de Comte no Rio Grande do Sul em uma palestra proferida em 1998 e publicada no mesmo ano sob o título O velho/novo positivismo, Sandra Pesavento destacou que as pesquisas recentemente desenvolvidas trouxeram novas indagações e abordagens, promovendo uma renovação da história política e da história cultural, com estudos exploratórios das dimensões simbólicas do político, do imaginário e das sensibilidades. Também ressaltou a redução da escala de análise, antes preocupada essencialmente com questões macroestruturais, e que recentemente também passou a abarcar a perspectiva da micro-história com o desenvolvimento de estudos biográficos. Destaca ainda a importância 
Paulo Pezat

da exploração ocorrida em novos acervos documentais antes vedados à pesquisa, como o Arquivo Borges de Medeiros, sob a guarda do Instituto Histórico e Geográfico do Rio Grande do Sul, e a Capela Positivista de Porto Alegre. Entretanto, chamou a atenção para um perigo: o de se tomar a influência do positivismo no Rio Grande do Sul como um marco redutor, em que tudo por ela é explicado (Pesavento, 1998, p. 62-64).

Também procurando interpretar o desenvolvimento recente da historiografia gaúcha no que diz respeito à influência do ideário positivista, Nelson Boeira publicou um artigo em 2002 intitulado O positivismo do Rio Grande do Sul: questões pendentes e temas para pesquisa, onde assinalou que o positivismo ainda acarreta um grande investimento ideológico, pois integra os aspectos identitários dos gaúchos. Demonstra tal afirmação com os episódios eleitorais ao governo estadual, quando a questão da herança política do castilhismo volta à tona, embora de forma inteiramente descontextualizada. Também ressalta o problema dos modismos culturais e acadêmicos, que impediriam que linhas de pesquisa tivessem continuidade e chegassem a resultados mais consistentes. Entretanto, fazendo um balanço, Boeira entende que são satisfatórios os resultados obtidos ao longo das últimas três décadas pela historiografia dedicada a estudar os reflexos do pensamento de Comte na história do Rio Grande do Sul, pois, antes disso, era voz corrente que o positivismo fora apenas um modismo superficial e efêmero. Porém, a identificação de um amplo acervo documental tem propiciado o aparecimento de dissertações, teses, artigos, ensaios e comunicações que demonstram a profundidade e a riqueza desse fenômeno. Contudo, Boeira reitera a observação feita por Sandra Pesavento no sentido de que é preciso evitar a sobrevalorização desse fenômeno. Finalmente, ele ainda lamenta a ausência de uma análise marxista da influência exercida pelo pensamento de Auguste Comte no Rio Grande do Sul, que, 
O positivismo na abordagem da recente historiografia gaúcha

no seu entender, seria fundamental para estabelecer um contraponto e possibilitar o avanço do debate.

Efetivamente, exageros nunca propiciam boas interpretações, e a supervalorização dos traços deixados pelo positivismo na história do Rio Grande do Sul pode servir mais à constituição de um vasto anedotário político do que à compreensão do significado profundo deste fenômeno, que só pode ser analisado de forma profícua mediante o abandono de posturas preconceituosas. Nesse sentido, as pesquisas desenvolvidas ao longo dos últimos anos parecem-me ter o mérito de superar um certo ranço característico de décadas anteriores. De fato, até em função da conjuntura política vivida pelo país naquele período, era compreensível a preeminência de uma perspectiva maniqueísta, a partir da qual a figura de Auguste Comte foi demonizada. Inegavelmente, para mais de uma geração de historiadores e de cientistas sociais brasileiros, o positivismo foi tomado como o "inimigo de estimação", isto é, como o sistema de idéias que os acadêmicos adoravam odiar, pois criticá-lo conferia, implicitamente, credibilidade a quem formulava a crítica, dispensando-lhe da tarefa de demonstrar a validade de suas assertivas teóricas.

Finalmente, gostaria de levantar alguns temas ainda inexplorados pela historiografia gaúcha e brasileira (visto que pesquisas de âmbito nacional também podem ser desenvolvidas a partir do sul do país) no que diz respeito à influência exercida pelo positivismo comtiano. Creio que ainda estão para ser elaborados estudos biográficos de Miguel Lemos e de Teixeira Mendes, os dois maiores expoentes do positivismo religioso no Brasil, bem como de João Luiz de Faria Santos, de Joaquim José Felizardo Júnior, de Barros Cassal, de Demétrio Ribeiro e outros positivistas gaúchos.

A necessidade de se estudar a influência positivista na pintura, na escultura e na estatuária desenvolvida no Rio Grande do Sul e no conjunto do país durante o início do período republicano já 
foi parcialmente suprida por José Murilo de Carvalho (em âmbito nacional) e por Arnoldo Doberstein (em âmbito estadual). Recentemente, a tese de doutorado em História que Elisabete Leal defendeu na Universidade Federal do Rio de Janeiro trouxe mais luzes sobre o assunto ${ }^{13}$. Porém, outros temas relacionados com a concepção de arte de Auguste Comte ainda permanecem inteiramente inexplorados, como a intensa produção poética dos positivistas religiosos e também as odes de natureza política publicadas quando da morte de Castilhos, por exemplo.

Outro tema ainda por ser explorado diz respeito às relações mantidas entre a Igreja Positivista do Brasil e a Igreja Católica, tanto em nível nacional como em nível estadual. Também os escritos de Miguel Lemos e de Teixeira Mendes acerca da política internacional mantida pelo Brasil ainda estão por receber a atenção devida.

Recebido em 20/05/2006.

Aprovado em 08/09/2006.

\section{Positivism in recent gaucha's historiography approach}

Abstract: The influence caused by positivism in the society of Rio Grande do Sul in the final decades of the 19th century and the beginning of the 20th century is one of the most characteristic features of the state's history and culture. From then on, this theme has been motivating a number of research and work on regional historiography. Initially, the approaches were highly influenced by the political situation and by the support or rejection to the power project implemented by the Republican Party in the State, during the First Republic. Later, between the 70's and 80 's, with more developed professionalization in the area, many of the historians and social scientists in the state, who conducted their masters and doctoral research in other states in Brazil and even abroad, focused their analyses in the aforementioned period and in special, on the results that the Auguste Comte's thought had caused in politics, society and culture in the southern part of the country. More recently, after the creation and consolidation of state graduate programs in history and other areas of the human sciences, positivism is still motivating new research, with data from documentation that was unavailable before and in new theoreticalmethodological approaches.

Key words: positivism - historiography - Rio Grande do Sul. 
O positivismo na abordagem da recente historiografia gaúcha

\section{Notas}

${ }^{1}$ As pesquisas visando à elaboração de dissertações de mestrado e de teses de doutorado na área das ciências humanas foram desenvolvidas pelos acadêmicos gaúchos, a partir do final da década de 1960 e, principalmente, ao longo da década de 1970, em universidades de São Paulo, do Rio de Janeiro e do exterior. Mais tarde, a partir de 1974, muitas dessas pesquisas começaram a ser desenvolvidas também no Rio Grande do Sul, em decorrência da criação do Curso de Mestrado em História da Pontifícia Universidade Católica do Rio Grande do Sul, que passou a oferecer o curso de doutorado a partir de 1986. Por sua vez, a Universidade Federal do Rio Grande do Sul criou seu Programa de Pós-Graduação em História em 1986, oferecendo o curso de mestrado em História a partir daquele ano e o de doutorado a partir de 1995. Já a Universidade do Vale do Rio dos Sinos (Unisinos) criou o seu curso de mestrado em 1987 e o de doutorado em 1999. A partir de 1998, a Universidade de Passo Fundo criou o seu curso de mestrado, o primeiro do Rio Grande do Sul fora da capital e arredores. Desse modo, ampliaram-se as possibilidades para o desenvolvimento de pesquisas na área de história do Rio Grande do Sul, o que acabou por se refletir também em um aumento do número de trabalhos específicos sobre a influência do positivismo no estado.

${ }^{2}$ Não apenas os historiadores e cientistas sociais gaúchos interessaram-se pelo estudo do positivismo. No campo da Filosofia deve-se mencionar a tese de doutorado defendida por Rejane Carrion, em 1977, na Sorbonne, sob a orientação de Georges Canguilhem, publicada em português no mesmo ano. Cf. CARRION, Rejane. A ideologia médico-social no sistema de A. Comte. Porto Alegre, Cadernos do IFCH/UFRGS, 1977.

${ }^{3}$ Publicada em 1980 de acordo com a referência que segue: Pesavento, Sandra Jatahy. República velha gaúcha: charqueadas, frigorificos, criadores. Porto Alegre: Movimento, 1980.

${ }^{4}$ Dissertação publicada de acordo com a seguinte referência: Reichel, Heloisa Jochims. A indústria têxtil no Rio Grande do Sul: 1910-1930. Porto Alegre: Mercado Aberto, 1980.

${ }^{5}$ Dissertação publicada de acordo com a referência que segue: Bakos, Margaret Marchiori. RS: escravismo e abolição. Porto Alegre: Mercado Aberto, 1982.

${ }^{6}$ Uma versão adaptada desta tese foi publicada de acordo com a referência seguinte: Pinto, Céli Regina Jardim. Positivismo - um projeto político alternativo (RS: 1889-1930). Porto Alegre: L\&PM, 1986.

${ }^{7}$ A tese originou dois livros, editados segundo as referências que seguem: Pesavento, Sandra Jatahy. A burguesia gaúcha: dominação do capital e disciplina do trabalho (RS 1889-

Anos 90, Porto Alegre, v. 13, n. 23/24, p.255-285, jan./dez. 2006 
Paulo Pezat

1930). Porto Alegre: Mercado Aberto, 1988; e Pesavento, Sandra Jatahy. Os industriais da República. Porto Alegre: Instituto Estadual do Livro, 1991.

${ }^{8}$ Tese editada de acordo com a referência que segue: Félix, Loiva Otero.

Coronelismo, borgismo e cooptação política. Porto Alegre: Mercado Aberto, 1987.

${ }^{9}$ Programa de fomento à cultura mantido desde meados da década de 1990 pela Secretaria Municipal de Cultura de Porto Alegre.

${ }^{10} \mathrm{O}$ referido catálogo possui a referência a seguir: Leal, Elisabete da Costa; Pezat, Paulo Ricardo. Capela Positivista de Porto Alegre: acervo bibliográfico, documental e iconográfico. Porto Alegre: Fumproarte/PPG-História da UFRGS, 1996.

${ }^{11}$ Obra editada naquele mesmo ano de acordo com a referência seguinte: Ismério, Clarisse. Mulher: a moral e o imaginário (1889-1930). Porto Alegre: EDIPUCRS, 1995.

${ }^{12}$ Esta tese foi agraciada com o Prix de Thèse Auguste Comte, conferido pela Associatin International Maison d'Auguste Comte, em Paris, onde estive desenvolvendo pesquisas em 2002 (sob a orientação da Prof ${ }^{a}$. Dr ${ }^{a}$ Annie Petit, da Université Montpellier III), graças ao apoio da Capes e do PPG-História da UFRGS.

${ }^{13}$ Ver Doberstein, Arnoldo Walter. Porto Alegre, 1900-1920: estatuária e ideologia. Porto Alegre: Secretaria Municipal de Cultura, 1992; e Leal, Elisabete da Costa. Filósofos em tintas e bronze: arte, positivismo e política na obra de Décio Villares e Eduardo de Sá. Rio de Janeiro: IFCS/UFRJ, 2006.

\section{Referências}

ABREU, Florêncio de. O movimento positivista no Rio Grande do Sul. In: Ensaios e estudos históricos. Rio de Janeiro: Irmãos Pongetti, 1964.

ALMEIDA, João Pio de. Borges de Medeiros - subsidios para o estudo de sua vida e de sua obra. Porto Alegre: Globo, 1928.

ALMEIDA, Marlene Medaglia. Inovações e recorrência do discurso historiográfico “oficial” no Rio Grande do Sul (1920-1935). In: Cadernos de Estudos do Programa de Pós-Graduação em Antropologia Social da UFGRS, Porto Alegre, n. 3, 1987.

AXT, Gunter. Gênese do Estado burocrático-burguês no Rio Grande do Sul (1889-1929). Tese de doutorado. Programa de Pós-graduação em História Social da FFLCH/ USP, São Paulo, 2001.

Os guardiães da lei: aspectos da influência política e cultural dos positivistas religiosos sobre os governos republicanos no Rio Grande do Sul. Métis: história \& cultura, Caxias do Sul, v. 1, n. 2, p. 33-52, jul./dez. 2002.

Anos 90, Porto Alegre, v. 13, n. 23/24, p.255-285, jan./dez. 2006 
O positivismo na abordagem da recente historiografia gaúcha

BAKOS, Margaret Marchiori. Republicanismo, Positivismo e imprensa político-partidária no Movimento Abolicionista no RS (1870-1888). Porto Alegre: PUCRS, 1982 (dissertação de mestrado em História).

BOEIRA, Nelson. O Rio Grande de Augusto Comte. In: DACANAL, José Hildebrando; GONZAGA, Sergius (org). RS: cultura e ideologia. Porto Alegre: Mercado Aberto, 1980. p. 34-59.

Comte in exile: the origins of political positivism in Rio Grande do Sul, Brazil, 1860-1891. New Haven: Yale University, 1993. (tese de doutorado em História).

O positivismo do Rio Grande do Sul: questões pendentes e temas para pesquisa. In: RECKZIEGEL, Ana Luiza; FÉLIX, Loiva Otero (org). RS: 200 anos defnindo espaços na história nacional. Passo Fundo: Editora da UPF, 2002. p. 237-246.

BOSI, Alfredo. Arqueologia do Estado-Providência - sobre um enxerto de idéias de longa duração. In: Companhia das Letras, 1992. p. 273-307. - Dialética da Colonização. São Paulo:

CASSOL, Ernesto. Carlos Torres Gonçalves, vida e obra. Erechim: Editora São Cristóvão, 2004.

COMTE, Auguste. Plano dos trabalhos científicos necessários para reorganizar a sociedade. In: Globo, 1899. p. 66-202.

DILL, Aidê Campello. A Criança sob Inspiração Positivista no Rio Grande do Sul (1898-1928). Porto Alegre: Programa de Pós-Graduação em História da PUCRS, 1999. (tese de doutorado em História).

DOBERSTEIN, Arnoldo. Porto Alegre, 1900-1920: estatuária e ideologia. Porto Alegre: Secretaria Municipal de Cultura, 1992.

ESCOBAR, Wenceslau. Apontamentos para a história da revolução Rio-Grandense de 1893. Porto Alegre: Globo, 1920.

FERREIRA FILHO, Arthur. História Geral do Rio Grande do Sul (1503-1957). Porto Alegre: Globo, 1958.

A influência positivista na política rio-grandense. Revista do Instituto de Filosofia e Ciências Humanas, Porto Alegre, UFGRS, ano IV, p. 277-286, 1976.

FRANCO, Sérgio da Costa. Júlio de Castilhos e sua época. Porto Alegre: Globo, 1967.

Anos 90, Porto Alegre, v. 13, n. 23/24, p.255-285, jan./dez. 2006 
Paulo Pezat

FREITAS, Décio. O bomem que inventou a ditadura no Brasil. Porto Alegre: Sulina, 1998.

GUTFREIND, Ieda. RS: 1889-1896. A Proclamação da República e a reação liberal através da imprensa. Porto Alegre: PUCRS, 1979. (dissertação de mestrado em História).

Historiografia sul-rio-grandense e o positivismo comtiano. In: GRAEBIN, Cleusa; LEAL, Elisabete (org). Revisitando o positivismo. Canoas: Editora La Salle, 1998. p. 47-58.

ISMÉRIO, Clarisse. A mulher na república velha: o imaginário e a realidade no RS (1889-1930). Porto Alegre: Programa de Pós-Graduação em História da PUCRS, 1995. (dissertação de mestrado em História).

JUNGBLUT, Cesar Augusto. "Júlio de Castilhos ainda vive?" - Imaginário político da República Velha Rio-Grandense (1903-1923). São Leopoldo: Programa de Pósgraduação em História da Unisinos, 1998. (dissertação de mestrado).

KLIEMANN, Luiza Helena Schmitz. A ferrovia gaúcha e as diretrizes de Ordem e Progresso. Porto Alegre: PUCRS, 1977. (dissertação de mestrado em História). Aberto, 1986.

RS: terra e poder - bistória da questão agrária. Porto Alegre: Mercado

LEAL, Elisabete da Costa. O positivismo, o Partido Republicano Rio-Grandense, a moral e a mulher (1891-1913). Porto Alegre: PPG-História / UFRGS, 1996. (dissertação de mestrado em História).

Filósofos em tintas e bronze: arte, positivismo e politica na obra de Décio Villares

e Eduardo de Sá. Rio de Janeiro: Instituto de Filosofia e Ciências Sociais / Universidade Federal do Rio de Janeiro, 2006. (tese de doutorado em História).

LEAL, Elisabete da Costa; PEZAT, Paulo Ricardo. Capela Positivista de Porto Alegre: acervo bibliográfico, documental e iconográfico. Porto Alegre: Fumproarte/ PPG-História da UFRGS, 1996.

LINS, Ivan. História do positivismo no Brasil. São Paulo: Companhia Editora Nacional, 1967.

LOVE, Joseph. O regionalismo gaúcho e as origens da revolução de 1930. São Paulo: Perspectiva, 1975.

PESAVENTO, Sandra Jatahy. Charqueadas, frigorificos e criadores: um estudo sobre a República Velha Gaúcha. Porto Alegre: PUCRS, 1978 (dissertação de mestrado em História).

Anos 90, Porto Alegre, v. 13, n. 23/24, p.255-285, jan./dez. 2006 


\section{O positivismo na abordagem da recente historiografia gaúcha}

Historiografia e ideologia. In: DACANAL, José Hildebrando; GONZAGA, Sergius (org). RS: cultura e ideologia. Porto Alegre: Mercado Aberto, 1980. p. 60-88.

Empresariado industrial, trabalho e Estado: contribuição a uma análise da burguesia industrial gaúcha. São Paulo: USP, 1987 (tese de doutorado em História Econômica).

O velho/novo positivismo. GRAEBIN, Cleusa; LEAL, Elisabete (org). Revisitando o positivismo. Canoas: Editora La Salle, 1998. p. 59-64.

PETERSEN, Sílvia Regina Ferraz. Historiografia positivista e positivismo comtiano: origem e desvirtuamento de uma relação teórica. In: GRAEBIN, Cleusa; LEAL, Elisabete (org). Revisitando o positivismo. Canoas: Editora La Salle, 1998. p. 31-46.

PEZAT, Paulo Ricardo. Auguste Comte e os fetichistas: estudo sobre as relações entre a Igreja Positivista do Brasil, o Partido Republicano Rio-grandense e a politica indigenista na República Velha. Porto Alegre: Programa de Pós-Graduação em História da Universidade Federal do Rio Grande do Sul, 1997 (dissertação de mestrado).

Carlos Torres Gonçalves, a família, a pátria e a bumanidade: a recepção do positivismo por um filho espiritual de Auguste Comte e de Clotilde de Vaux no Brasil (1875-1974). Porto Alegre: Programa de Pós-Graduação em História da Universidade Federal do Rio Grande do Sul, 2003 (tese de doutorado em História).

PINTO, Céli Regina Jardim. Contribuição ao Estudo da Formação do Partido Republicano Rio-grandense. Porto Alegre: UFRGS, 1979 (dissertação de mestrado em Ciência Política). L\&PM, 1986.

Positivismo - um projeto político alternativo (RS: 1889-1930). Porto Alegre:

REICHEL, Heloísa Jochims. A indústria têxtil no Rio Grande do Sul: 1910-1930. Porto Alegre: PUCRS, 1978 (dissertação de mestrado).

RODRIGUEZ, Ricardo Velez. Castilhismo - uma filosofia da República. Porto Alegre: Escola Superior de Teologia; Caxias do Sul: Universidade de Caxias do Sul, 1980 .

ROSA, Othelo. Júlio de Castilhos - perfil biographico e escriptos politicos. Porto Alegre: Globo, 1928. 


\section{Paulo Pezat}

SOARES, Mozart Pereira. O positivismo no Brasil: 200 anos de Augusto Comte. Porto Alegre: AGE / Editora da UFRGS, 1998.

SPONCHIADO, Breno. O positivismo e a colonização do norte do Rio Grande do Sul. Porto Alegre: Programa de Pós-Graduação em História / PUCRS, 2000 (dissertação de mestrado).

TRINDADE, Hélgio. O jacobinismo castilhista e a ditadura positivista no Rio Grande do Sul. Revista do Instituto de Filosofia e Ciências Humanas, Porto Alegre, UFRGS, n. 14, p. 93-103, 1990.

TRINDADE, Hélgio (org). Positivismo: teoria e prática. Porto Alegre: Editora da UFGRS, 1999.

WEBER, Beatriz Teixeira. As artes de curar: medicina, religião, magia e positivismo na República Rio-Grandense (1889-1928). Santa Maria: Ed. da UFSM; Bauru: EDUSC, 1999. 